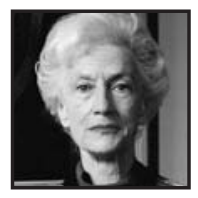

\title{
Commentary:
}

\section{The Genesis of Student Engagement}

\author{
Gretta Chambers, Chancellor Emerita, McGill University
}

\begin{abstract}
The premise here is that learning is the focal point of the student condition and therefore, learners are the principal beneficiaries of any educational process. Considerable effort goes into making allowances for the fact that all students do not learn with the same ease or difficulty and that individual learning paths can be very different. My contention here is that the most important piece in the whole education conundrum is the attitude of learners towards the experience itself and that it is on that attitude in particular that their engagement in the process depends.
\end{abstract}

$s$ learning is the focal point of educational institutions, the learners are the principal beneficiaries of any educational process. Learning however is not like eating and therefore digesting, hearing and therefore recognizing sound, seeing and therefore absorbing a view. The results of eating, hearing and seeing are the naturally induced conditions of the use of the senses. The learning phenomenon is more often than not treated as though it were a matter of being presented with knowledge considered appropriate to the time and circumstances of the learner in question for the subject matter to be assimilated.

Great efforts are made, and rightly so, to allow for the fact that everyone does not learn in the same manner, that everyone does not necessarily grasp concepts with the same facility or difficulty. Myriad social and physical reasons mitigate uniformity in the learning experience. But no matter what the accommodations put in place to help level the learning field, no matter how good and inspiring the teachers 
who make such a difference to the experience, if the potential learners are not engaged in the process, what they get out of it will fall short of what is expected of it. In my view, the most important piece in the whole education conundrum is the attitude of learners towards the experience itself. That attitude will colour their response to the subject matter to which they are being exposed.

Schools, colleges and universities are portrayed as venues for the advancement of learning from basic literacy to the most advanced training in the sciences, the humanities and the professions. Out of universities comes the research that now fuels economic development; out of all educational institutions comes the knowledge and know-how to contribute to personal and societal social and economic advancement. There is very little debate about any of that. Even those who do not see education as the driving force of their own financial security, recognize its importance in the larger scale of a society's economy. When I was young, the school of hard knocks had a quite respectable reputation particularly when discussing those who seemed to have thrived on its curricula. It is a very different story today when a young person looking for a "good" job must often pass the "diploma" test before being considered for employment in any capacity. So, if no one disputes the fact that more learning makes for better earning, how is it that we have not managed to persuade such a dangerously large proportion of our young people, particularly young men, that learning is good for them. We are not engaging them in the learning experience.

Children and young adults who come from families in which learning is highly prized, who have been brought up surrounded by books and other manifestations of knowledge come to the learning process as though to the manor born. Even the rebellious have an intrinsic understanding of learning as a way of acquiring information. They may become very selective about what they want to know but they have assimilated the connection between their part in the learning process and what they are likely to get out of it. Successful schools are those which keep their students engaged from Kindergarten to Secondary V. Successful schools are those which provide their students with the ingredients they need to make it feel safe and satisfying to engage in the process.

We talk a great deal about the role education and learning play in a person's earning power, and I have just joined in that chorus of opinion. It is a circumstance that is hard to gainsay in our day and age. What we talk and think much less about is the role of education and learning in a person's living experience. So many of the children in our schools do not have the good fortune of having a good life at home. They come to school because they have to find a haven in some way. Before those children 
can become engaged in learning, they have to feel safe and sustained. We tend to feel that the just and generous culture of our society is reflected in our scholastic institutions, that we are providing nurturing for all students in our school system. But this does not appear to be universally accepted as a given by significant numbers of school children.

Across the world there are hundreds of millions of children who don't go to school at all. Famine, wars, genocides, abduction, slavery, mutilation, the HIV/AIDS pandemic and other horrors perpetrated against poor and helpless people in many parts of the globe have left countless children without parents, shelter, arms and legs, and security of any kind. The misery found in many parts of Africa is hard to contemplate and seems impossible to alleviate in any definitive way. NGOs, international aid, the World Bank, the IMF, the WFO and the G8 have not yet come to the rescue of these destitute people in any sustained way. The UNICEF annual "State of the World's Children" report quoted former Tanzanian President Julius Nyerere's question, "Must we starve our children to pay our debts?"The answer continues it seems, to be "Yes." And, as all those who witness the situation on the ground continue to report, the world's financial and governmental establishments are still not honouring their commitments.

Information, about the area and its plight, however, is plentiful and quite startling. There have been several surveys undertaken by international organizations, like UNICEF, to ascertain what could be done specifically about the plight of children. Every one of these extensive enquiries came up with the same major finding. The one thing these children want more than anything-and many of them are in serious want-is a school to go to. They talked about some safe place where they could learn. Their hunger for learning, for a place to learn, was universal. These potential students are already engaged in their yearning for access to the learning experience which to them represents normality and the stability to regenerate the purpose of their lives. Something else that the sociology of struggling Africa shows is that the regions which have succeeded in finding some form of social and political stability and the beginnings of economic development are places which have managed to educate women who, in many areas, have become the driving forces of the school system. In struggling societies, the education of women is the greatest spur to social and economic progress. These are societies where education has not been widely available to women in the past. Today, it is being embraced by women to tremendous benefit, not only to the women themselves, but also to the communities to which they belong. The level of their engagement is as strong as it has become productive. 
We see by these extreme examples, that engagement depends, not only on propitious settings, approaches and products but also on a hunger for self-protection, self-worth and self-improvement. That could be one of the reasons that the dropout rate among young women high school students is so much lower than it is among young men. Even in our privileged and equity-minded society, women are still much more vulnerable than men in countless ways and their instincts are geared to acquiring all the protective knowledge that learning can bring them.

Students at the postsecondary level tend to be already engaged if only tenuously. Those aiming at professional training have little choice but to engage in the learning process with specific targets in view. As they say, there is nothing that better concentrates the mind than the threat of imminent failure. These students have a reason that they themselves have chosen for going to university.

There are, however, even more college and university students who are there because that is where their schooling, their parents or an apparent lack of alternatives leads them to enroll. And engaging these unfocused young people can be a challenge. So many arrive at the postsecondary level with no goals in mind. Giving personally relevant and professionally useful meaning to the experience and the often boring course work are not necessarily part of the curricula. Education, apart from making them more employable in general, also gives them a better chance of making a success of their personal lives. A university education opens a door in the mind that will never close and that can afford ongoing learning possibilities.

One can lose money, friends, health, jobs, etcetera, but one can never lose what one has learned. Education is for life and its benefits-tangible and intangible-become an intrinsic part of a person's psyche and perspective. Pursuing the abstract nature of "education" for its own sake is an objective that is hard to instill in the young with little sense of direction. How many times have we all heard young women say, "Why would I need a college education if all I'm going to do is stay home and change diapers?" Little do they realize how valuable an education is to someone engaged in boring tasks, on the one hand, and, on the other, what a difference it can make to how one brings up one's children.

Engaging young minds in higher education is becoming an ongoing concern for postsecondary institutions. Academics and administrators have begun to hone in on some of the important extraneous reasons that keep students "hooked" on college and university learning. These reasons have been found to have many aspects in common with what makes wounded, displaced children long for school. 
Disconnected high school, college and university students stick it out to graduation if they feel comfortable with the learning experience to which they are being subjected and if they can relate to at least some part of its content. Sometimes it takes only one course, more often than not, one teacher to break through the wall of irrelevance that so many of today's students face when it comes to the venues and contents of academic endeavor.

CEGEP and university administrations are putting more and more effort into addressing what students themselves feel they need to make the whole experience of college/university life satisfying, engaging and rewarding. All probing of students' attitudes towards the institution they attend suggests that insecurity due to a seemingly completely depersonalized existence can give newly minted students a feeling of being alone in a foreign setting. Often, by the time they can find their way through the academic and bureaucratic maze in which they find themselves, they have already jeopardized their term, if not their year. Better counseling, a more direct monitoring of progress right from the beginning and more visible support systems through academic and administrative hurdles also help to engage students in the "community" process on their way to finding their own intellectual engagement in the satisfaction of having learned. This inevitably follows a successfully executed effort at doing the work required.

Universities are faced with somewhat the same basic problems. Making students feel part of a community of scholarship rather than simply as individual numbers in a series of numbered courses is part of a fairly new nurturing concept. Better counseling, more streamlined and accessible administrative information and services and a more overtly student-centred approach to institutional bureaucracy are now part of an attempt at finding a more "engaging" approach to plugging students right from the outset into the potential benefits of joining the community of scholarship that surrounds them.

One of the experiments being undertaken at this level is the creation of elective undergraduate seminars modeled on postgraduate research based seminars. The idea here is to introduce undergraduates to a hands-on approach to the learning experience that students are not generally exposed to until much later in their academic careers. This is an experiment in engagement aimed at exposing undergraduate students to the intense pressure of digging up their own original information in the development of course and discussion content. 
The most encouraging aspect of the "engagement" question is that it appears to now be accepted as a more and more important condition of the learning process. There is a widely recognized need to establish the engagement of students before the success in the learning experience can be considered readily achievable at all levels of the education continuum. Our society can so easily lose sight of the basic nature of an engagement that drives humanity's social structures and perspectives. The immediacy of our world and its imperatives overshadow the significance of how we got here. Civil society as we know it, and imperfect as it is, has come about through the acquisition of knowledge which has widened humanity's horizons and replaced violence as the main source of progress with quality of life enhancement. Contexts and goals change but the basic principle remains. Today, children and young adults who do not necessarily learn about the benefits of acquiring knowledge at home must find the ways and means of joining the quest for a better life for themselves on the way to joining the composite future.

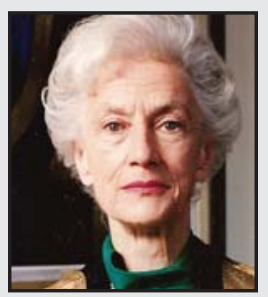

Gretta Chambers graduated from McGill in 1947 with a B.A. in Political Science and History. Most of her professional career has been spent working in radio, television and print media as a political commentator. She has been very active in community work on commissions, boards and councils dealing with Social Services, Education, Cultural institutions, Legal and Judicial councils, Public Security questions, Health and Safely in the Workplace and Women's issues. She is a Companion of the Order of Canada and an Officer of the Order of Quebec. She has been a Governor of McGill University's Board of Governor since 1978 and served as Chancellor of the University from 1991 to 1999 when she was named Chancellor Emerita. 